\title{
Structural and Evolutionary Relationships of $\beta$-Lactamase Transposons from Staphylococcus aureus
}

\author{
By MATTHEW T. GILLESPIE, $\dagger$ BRUCE R. LYON \\ AND RONALD A. SKURRAY* \\ Department of Microbiology, Monash University, Clayton, Victoria 3168, Australia
}

(Received 15 July 1988)

A comparison of the $\beta$-lactamase elements detected on three classes of large plasmids together with the chromosomes of penicillin-resistant Staphylococcus aureus revealed substantial physical and genetic relatedness. In most cases, $\beta$-lactamase production could be associated with the presence of a DNA segment of approximately $6.7 \mathrm{~kb}$. Analysis showed that the plasmid-borne determinants constitute nearly identical transposons or transposon-like elements. An element indistinguishable from one of these, Tn4002, which is carried by the pSK1 family of plasmids in clinical isolates from Australian hospitals, was also identified on the staphylococcal chromosome and is implicated in an evolutionary cycle of transposition between chromosomal and extrachromosomal sites in Australian strains of multiresistant $S$. aureus.

\section{INTRODUCTION}

Penicillin resistance $\left(\mathrm{Pc}^{r}\right)$ is often mediated by a $\beta$-lactamase (penicillinase) which inactivates the antibiotic through hydrolysis of the $\beta$-lactam ring. The enzymes responsible for $\mathrm{Pc}^{\mathrm{r}}$ in Staphylococcus aureus have been historically associated with large plasmids (about $30 \mathrm{~kb}$ ) which additionally encode resistance to the heavy metals including arsenate (Asa), arsenite (Asi), cadmium (Cd) and mercury (Hg) (Peyru et al., 1969; Shalita et al., 1980). Murphy \& Novick (1979) suggested that the $\mathrm{Pc}^{r}$ determinant of these plasmids may reside on a transposon, designated $\operatorname{Tn} 552$, which can translocate from a chromosomal to a plasmid site.

In recent years, $\mathrm{Pc}^{\mathrm{r}}$ in $S$. aureus isolates from the USA and Europe has been attributed either to $\beta$-lactamase/heavy metal resistance plasmids or to the presence of a family of selftransmissible plasmids which also encode resistance to the aminoglycosides gentamicin $(\mathrm{Gm})$, tobramycin $(\mathrm{Tm})$ and kanamycin $(\mathrm{Km})$ and to quaternary ammonium compounds $(\mathrm{Qa})$ and ethidium bromide (Eb) (Goering \& Ruff, 1983; Witte \& Dünnhaupt, 1984). The $\mathrm{Pc}^{\mathrm{r}}$ region of one of these plasmids, pCRG1600, was shown to lie within a $6.7 \mathrm{~kb}$ transposon, designated Tn 4201, which is capable of undergoing rec-independent translocation between plasmids and the chromosome (Weber \& Goering, 1988).

Plasmids similar or identical to the $\beta$-lactamase/heavy metal resistance plasmids have been identified in Australian isolates of $S$. aureus from the mid-1940s; however, since the early 1970s, $\mathrm{Pc}^{\mathrm{r}}$ has been found to be predominantly determined by the chromosome (Lyon et al., 1983; Gillespie et al., 1985, 1986 b). In recent years, a determinant for $\mathrm{Pc}^{\mathrm{r}}$ has been detected on some members of a unique family of $\mathrm{Eb}^{\mathrm{r}} \mathrm{Qa}^{\mathrm{r}}$ and acriflavine resistance $\left(\mathrm{Ac}^{\mathrm{r}}\right)$ plasmids which often additionally encode $\mathrm{Gm}^{\mathrm{r}} \mathrm{Tm}^{\mathrm{r}} \mathrm{Km}^{\mathrm{r}}$ via $\mathrm{Tn} 4001$ and/or trimethoprim resistance $\left(\mathrm{Tp}^{\mathrm{r}}\right.$ ) through the carriage of a unique dihydrofolate reductase determinant (dfrA) on the transposon $\operatorname{Tn} 4003$ (Gillespie \& Skurray, 1986; Lyon \& Skurray, 1987; Lyon et al., 1987; Young et al., 1987; Skurray

\footnotetext{
$\dagger$ Present address: Department of Medicine, The University of Melbourne, Repatriation General Hospital Heidelberg, Heidelberg West, Victoria 3081, Australia.

$\ddagger$ Present address: CSIRO Division of Plant Industry, Canberra, ACT 2601, Australia.
} 
Table 1. Characteristics of $S$. aureus plasmids and strains

\begin{tabular}{lll} 
& $\begin{array}{r}\text { Year of } \\
\text { isolation }\end{array}$ & \multicolumn{1}{c}{ Resistance to* } \\
Plasmid & & \\
pSK1 & 1980 & GmTmKmAcEbQaTp \\
pSK4 & 1981 & GmTmKmAcEbQaTpPc \\
pSK8 & 1981 & GmTmKmAcEbQaTpPc \\
pSK11 & 1980 & GmTmKmTpPc \\
pSK15 & 1982 & GmTmKmAcEbQaPc \\
pSK16 & 1982 & GmTmKmAcEbQaTpPc \\
pSK17 & 1981 & GmTmKmAcEbQPc \\
pSK41 & 1977 & GmTmKmNmPmEbQa \\
pUW3626 & 1981 & GmTmKmNmPmEbQaPc \\
pI524 & & PcAsaAsiCdHg \\
pSK74 & 1953 & PcAsaAsiCdHg \\
Strain & & \\
SK1655 & 1965 & SmTc \\
SK1660 & 1976 & PcMcSmTcEmCdHg \\
SK1717 & 1977 & PcMcSmTcEmGmTmKmNmAkCdHg \\
SK1734 & 1978 & PcMcSmTcEmGmTmKmNmCmCdHg \\
SK1903 & 1978 & PcSmTcGmTmKmCd \\
SK460 & 1981 & PcMcSmTcEmGmTmKmNmAkCdHg \\
SK1589 & 1981 & PcMcSmTcEmCmCdHg \\
SK1591 & 1981 & PcSmTcEm
\end{tabular}

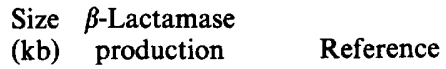

\begin{tabular}{|c|c|c|}
\hline $28 \cdot 4$ & - & Lyon et al. (1987) \\
\hline $35 \cdot 1$ & + & Gillespie et al. (1987b) \\
\hline $35 \cdot 1$ & + & Gillespie et al. (1987b) \\
\hline $41 \cdot 8$ & + & Gillespie et al. (1987b) \\
\hline $31 \cdot 1$ & + & Gillespie et al. (1987b) \\
\hline $35 \cdot 1$ & + & Gillespie et al. $(1987 b)$ \\
\hline $36 \cdot 4$ & + & Gillespie et al. (1987b) \\
\hline $47 \cdot 8$ & - & Lyon et al. (1987) \\
\hline $54 \cdot 4$ & + & Lyon et al. (1987) \\
\hline $31 \cdot 8$ & + & Murphy \& Novick (1979 \\
\hline $31 \cdot 8$ & + & Gillespie et al. (1985) \\
\hline & - & Gillespie et al. (1987a) \\
\hline & + & Gillespie et al. $(1987 b)$ \\
\hline & + & Gillespie et al. (1987b) \\
\hline & + & Gillespie et al. (1987b) \\
\hline & + & Gillespie et al. (1987b) \\
\hline & + & Gillespie et al. $(1987 b)$ \\
\hline & + & Gillespie et al. (1987b) \\
\hline & + & Gillespie et al. (1986a) \\
\hline
\end{tabular}

* Ac, acriflavine; Ak, amikacin; Asa, arsenate; Asi, arsenite; Cd, cadmium; Cm, chloramphenicol; Eb, ethidium bromide; Em, erythromycin; Gm, gentamicin; $\mathrm{Hg}$, mercury; Km, kanamycin; Mc, methicillin; $\mathrm{Nm}$, neomycin; Pc, penicillin; Pm, paromomycin; Qa, quaternary ammonium compounds; Sm, streptomycin; Tc, tetracycline; Tm, tobramycin; Tp, trimethoprim.

et al., 1988). We have investigated the nature of the $\mathrm{Pc}^{\mathrm{r}}$ determinants in Australian isolates of $S$. aureus and in this paper we report our findings, compare these determinants with $\mathrm{Tn} 552$ and a Tn4201-like element from the self-transmissible plasmid pUW3626, and provide evidence for the evolutionary spread of $\mathrm{Pc}^{\mathrm{r}}$ determinants between different plasmids and the chromosome.

\section{METHODS}

Bacterial plasmids and strains. These are listed in Table 1, together with relevant characteristics. We are grateful to G. K. Best, Medical College of Georgia, USA, M. L. Cohen, Center for Infectious Diseases, Atlanta, Georgia, USA, and R. P. Novick, Public Health Research Institute of the City of New York, USA, for providing strains containing plasmids pSK41, pUW3626 and pI524, respectively.

General procedures. Standard culture media and methods for the determination of $\beta$-lactamase production and resistance to antimicrobials and heavy metals were as previously described (Lyon et al., 1983; Gillespie et al., 1985).

DNA manipulations and analysis. The isolation of purified plasmid DNA and whole-cell DNA, digestion with restriction endonucleases, agarose gel electrophoresis, the estimation of DNA fragment sizes, and all recombinant DNA techniques were done as reported previously (Lyon et al., 1983, 1984a, 1987). The isolation and radiolabelling of DNA probes, DNA-DNA hybridization, and examination of heteroduplexed DNA by electron microscopy were done essentially as described in earlier papers (Lyon et al., 1984b, 1987; Gillespie et al., 1986b).

\section{RESULTS AND DISCUSSION}

\section{$\beta$-Lactamase transposons on $S$. aureus plasmids}

The $35.1 \mathrm{~kb}$ plasmid pSK4 (Lyon et al., 1983; Gillespie et al., 1987 b), in addition to encoding $\mathrm{Ac}^{\mathrm{r}} \mathrm{Eb}^{\mathrm{r}} \mathrm{Qa}^{\mathrm{r}}, \mathrm{Gm}^{\mathrm{r}} \mathrm{Tm}^{\mathrm{r}} \mathrm{Km}^{\mathrm{r}}$ and $\mathrm{Tp} \mathrm{p}^{\mathrm{r}}$, was shown to encode $\mathrm{Pc}^{\mathrm{r}}$ via the production of a $\beta$ lactamase. Comparative restriction analysis revealed that pSK4 differed from the $28.4 \mathrm{~kb}$ $\mathrm{Ac}^{\mathrm{r}} \mathrm{Eb}^{\mathrm{r}} \mathrm{Qa}^{\mathrm{r}}, \mathrm{Gm}^{\mathrm{r}} \mathrm{Tm}^{\mathrm{r}} \mathrm{Km}^{\mathrm{r}}$ and $\mathrm{Tp}^{\mathrm{r}}$ plasmid $\mathrm{pSK} 1$ only through the possession of an additional 6.7 $\mathrm{kb}$ insert of DNA lying between the $\mathrm{Tp}^{\mathrm{r}}$ and $\mathrm{Ac}^{\mathrm{r}} \mathrm{Eb}^{\mathrm{r}} \mathrm{Qa}^{\mathrm{r}}$ determinants (dfr $A$ and qacA, respectively) (Fig. 1). Another five plasmids (pSK8, pSK11, pSK15, pSK16 and pSK17) were 


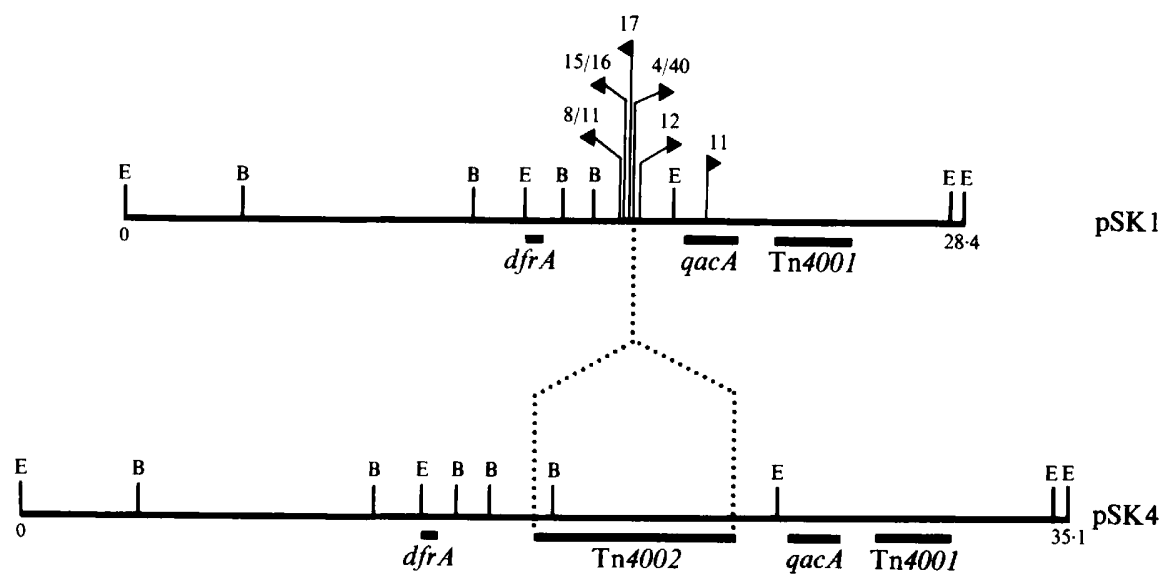

Fig. 1. Comparative restriction maps of $\mathrm{pSK} 1$ and $\mathrm{Pcr}^{\mathrm{r}}$ plasmid pSK4. Restriction endonuclease sites are indicated by $B(B g / \mathrm{II})$ and $E(E c o R I)$. The sites of insertion and relative orientations (indicated by the arrowheads) of the $6.7 \mathrm{~kb} \mathrm{Pc}^{-}$transposon Tn4002 in the plasmids pSK4, pSK8, pSK11, pSK12, pSK15, pSK16, pSK 17 and pSK 40 are indicated on the map of the prototype Pc ${ }^{\text {s }}$ plasmid pSK1. Regions encoding $\mathrm{Tp}^{\mathrm{r}}($ dfr $A), \mathrm{Ac}^{r} \mathrm{~Eb}^{\mathrm{r}} \mathrm{Qa}^{\mathrm{r}}(q a c A)$ and the transposon encoding $\mathrm{Gm}^{\mathrm{r}}, \mathrm{Tm}^{\mathrm{r}}$ and $\mathrm{Km}^{\mathrm{r}}(\mathrm{Tn} 4001)$ are also indicated.

found to have insertions of identical size and restriction pattern at demonstrably different sites and in the opposite orientation to that in pSK4 (Fig. 1). One of the plasmids, pSK11, was shown to possess two such insertions, the first at an identical site to pSK8 and the second within qacA, resulting in an $\mathrm{Ac}^{\mathrm{s}} \mathrm{Eb}^{\mathrm{s}} \mathrm{Qa}^{\mathrm{s}}$ plasmid phenotype.

Although the different sites of insertion exhibited some degree of regional specificity, the orientation independence of the insert, together with demonstrated insertional inactivation, suggested that the $6.7 \mathrm{~kb} \mathrm{Pc}^{\mathrm{r}}$ region on these plasmids might be transposable. In agreement with this, genetic evidence for the translocation of a $6.7 \mathrm{~kb} \mathrm{Pr}$ element from chromosome to plasmid was obtained by the detection of two insert-bearing derivatives of pSK 1 following storage of strains of $S$. aureus bearing pSK 1 and a chromosomal Pcr determinant. One of the resultant plasmids, pSK 40, was indistinguishable from pSK4, whereas the other, pSK12, had suffered a $1.1 \mathrm{~kb}$ deletion immediately to the left of the $6.7 \mathrm{~kb}$ DNA insert (Fig. 1).

Heteroduplex analysis of pSK 4 and pSK1 (Fig. $2 a$ ), revealed a $6.5 \pm 0.06 \mathrm{~kb}$ single-stranded DNA segment flanked by terminal inverted repeats of less than $80 \mathrm{bp}$; a total of three molecules formed between pSK1 and pSK4 were examined as were six molecules with a similar transposon-like structure formed in heteroduplexes between pSK1 and pSK 8 (data not shown), Together, the genetic and physical data indicated that the $\mathrm{Pc}^{\mathrm{r}}$ determinant detected on members of the pSK1 family of $\mathrm{Ac}^{\mathrm{r}} \mathrm{Eb}^{\mathrm{r}} \mathrm{Qa}^{\mathrm{r}}$ plasmids comprised a transposable element, which we have designated Tn4002 (Gillespie \& Skurray, 1986; Lyon \& Skurray, 1987).

In a manner similar to that detailed above, heteroduplexes were generated between the selftransmissible plasmid pUW3626, which is highly related to pCRG1600 (Goering et al., 1985) and probably carries a Pcr element similar to Tn4201 on that plasmid (Weber \& Goering, 1988), and the $\beta$-lactamase-negative plasmid pSK41, which lacks a Tn4201-like element but is otherwise identical to pUW3626 (Lyon et al., 1987). Heteroduplexes between these two plasmids exhibited a $6 \cdot 6 \pm 0.5 \mathrm{~kb}$ structure composed of a single-stranded loop with inverted repeat sequences of less than $80 \mathrm{bp}$ (results from six molecules) (Fig. 2b). Hence, the $\mathrm{Pc}^{\mathrm{r}}$ transposon Tn4002 and the Tn4201-like element on pUW3626 possess several common characteristics. In order to conduct further comparisons both between these elements and with the $\beta$-lactamase transposon Tn552, detailed restriction maps of the plasmids carrying these $\beta$-lactamase elements were prepared.

Tn552 resides on the $31.8 \mathrm{~kb}$ heavy-metal-resistance plasmid pI524 (Murphy \& Novick, 1979), which we have shown by extensive restriction and hybridization analysis to be equivalent 

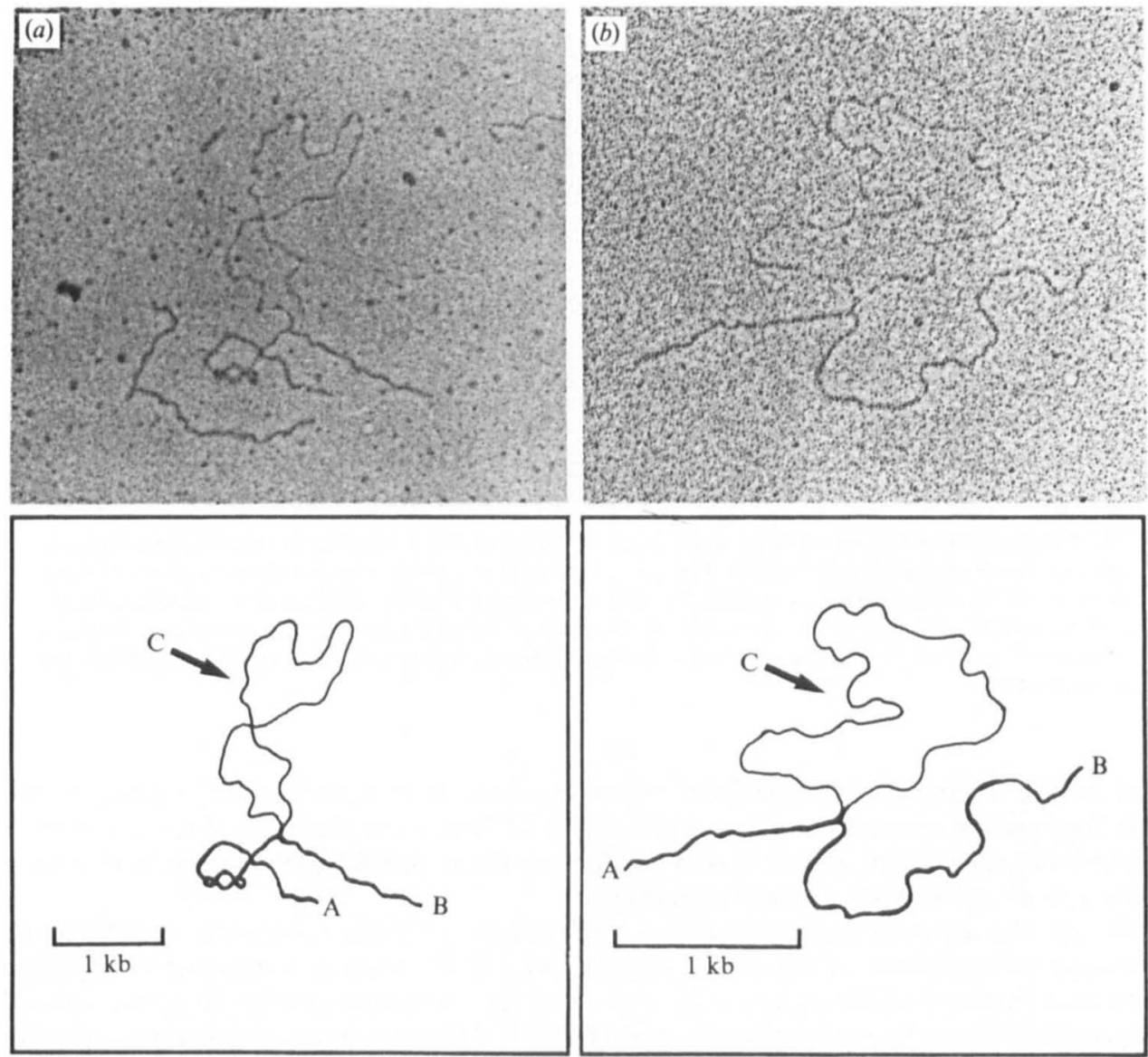

Fig. 2. Electron micrographs of heteroduplexes between $(a)$ pSK 1 and pSK4 and $(b)$ pSK 41 and pUW3626. Plasmid DNA was cleaved with EcoRI and the ends of the heteroduplexed fragments are designated A and B. In (a), ends A and B correspond to the EcoRI sites at coordinates 13.55 and $25.35 \mathrm{~kb}$ of pSK4, while in (b) ends A and B denote the EcoRI sites at pUW3626 map coordinates 42.8 and $54.4 \mathrm{~kb}$ (see Fig. 3). The arrow marked $\mathrm{C}$ indicates the single-stranded loop and short doublestranded stem of the $\mathrm{Pc}^{r}$ region of $(a)$ pSK4 (Tn4002) and $(b)$ pUW3626.

to pSK74, a plasmid isolated from Australian isolates of $S$. aureus (Gillespie et al., 1985). The $\beta$ lactamase region of pI524/pSK 74 consists of two segments (Fig. 3). The first is composed of the $\beta$-lactamase structural gene (blaZ) and the gene for negative control of $\beta$-lactamase production (blaI), and the second, inv, comprises a $2.2 \mathrm{~kb}$ region of DNA flanked by $650 \mathrm{bp}$ inverted repeat sequences $\left(\mathrm{IR}_{\mathrm{L}}\right.$ and $\mathrm{IR}_{\mathrm{R}}$ ) which can undergo reversible rec-independent inversion (Murphy \& Novick, 1979). The orientation of $i n v$ can be determined from the position of asymmetrically located restriction sites, and analysis of pI524/pSK 74 has revealed the presence of subpopulations of molecules bearing inv in both the positive and negative orientations (see Murphy \& Novick, 1979).

The $\beta$-lactamase region of $\mathrm{pI} 524 / \mathrm{pSK} 74$ was found to share substantial restriction similarity with the $\beta$-lactamase regions of pSK4 (Tn4002) and pUW3626 (Fig. 3). The blaI and blaZ segments on these plasmids appeared indistinguishable, and hybridization analysis using the $b l a$-specific $0.8 \mathrm{~kb}$ HindIII-XbaI fragment derived from pSK 74 as a ${ }^{32} \mathrm{P}$-labelled probe supported this result (data not presented). That the $0.8 \mathrm{~kb}$ HindIII-XbaI fragment includes sequences of the $\beta$-lactamase structural gene (blaZ) has been determined by $\operatorname{Tn} 5$ mutagenesis of cloned fragments of pSK 4 in our laboratory, and by the nucleotide sequencing of the blaZ gene from the heavy-metal-resistance plasmid pI258 (McLaughlin et al., 1981; Wang \& Novick, 


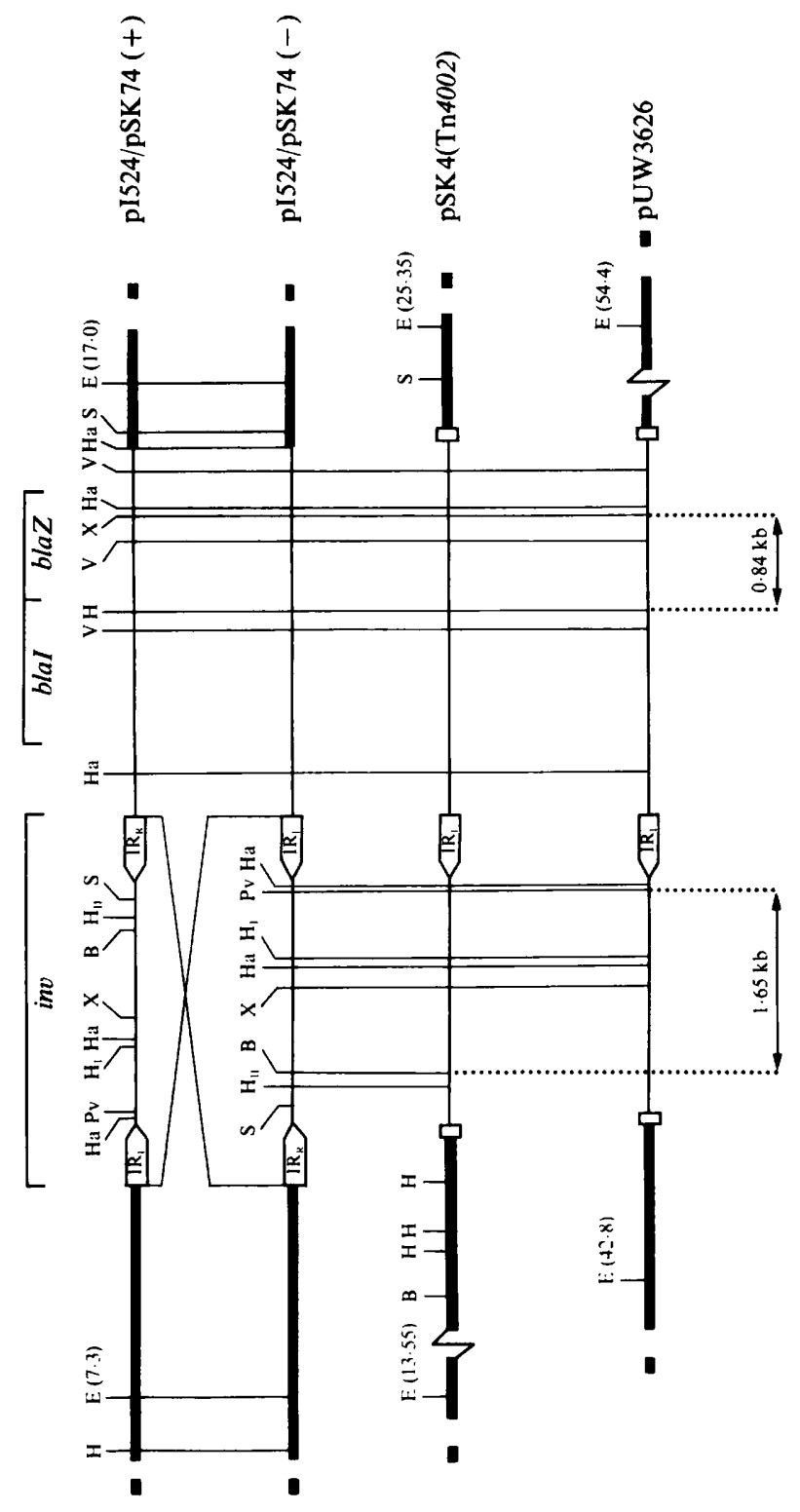

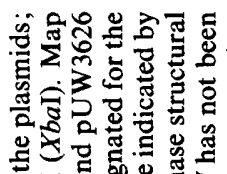

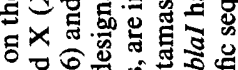
S

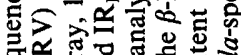
कै 넌 学.

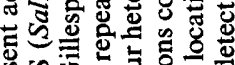

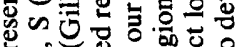
可

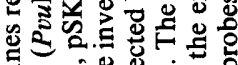

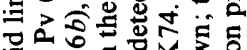

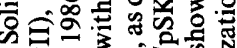

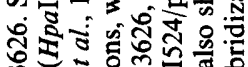

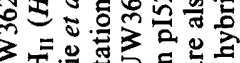

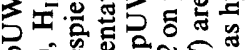
च 广

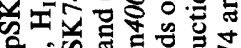

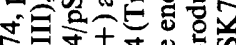

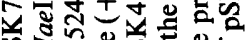

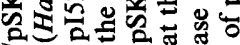

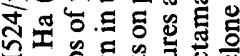
a

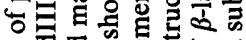

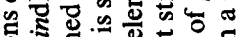

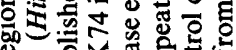

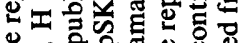

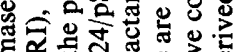

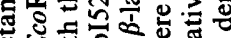

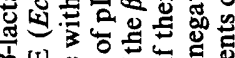

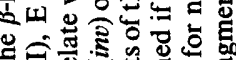

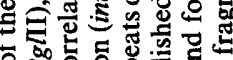
웅

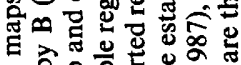

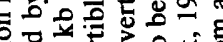

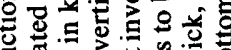

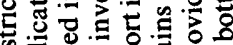

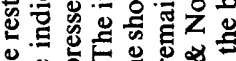

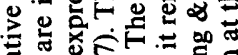
氙

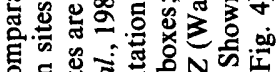

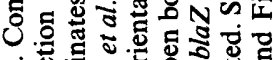

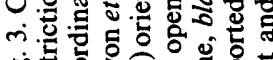

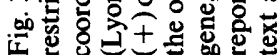


1987); the blaZ gene on the latter plasmid is equivalent to that encoded on pSK4, pSK74 and pUW3626 on the basis of restriction mapping and DNA hybridization (unpublished data). Some variance was detected in the remainder of the $\beta$-lactamase region, with $\mathrm{pI} 524 / \mathrm{pSK} 74$ and pSK 4 sharing seven of the eight restriction sites determined in the inv segment, and pUW3626 possessing five of these sites (Fig. 3). In both Tn 4002 on pSK 4 and the Pcr element on pUW3626, inv appeared to be incapable of inversion, existing solely in the negative orientation of the inversion, a consequence, perhaps, of the absence of $I_{R}$. Recently, Weber \& Goering (1988) have reported a restriction analysis of the $\mathrm{Pc}^{\mathrm{r}}$ transposon $\mathrm{Tn} 4201$ from the self-transmissible plasmid pCRG1600. Comparison of restriction maps indicates that Tn4201 is related to $\operatorname{Tn} 4002$ and to the $\mathrm{Pc}^{\mathrm{r}}$ regions of $\mathrm{pI} 524 / \mathrm{pSK} 74$ and pUW3626; from the arrangement of restriction sites, Tn4201 also carries inv in the negative orientation (Weber \& Goering, 1988).

Restriction endonuclease, DNA hybridization and homoduplex/heteroduplex analyses have demonstrated that other members of the pSK1 plasmid family (viz. pSK8, pSK11, pSK12, pSK15, pSK 16, pSK 17 and pSK40) also carry Tn4002 (data not presented). Similar studies on heavy-metal-resistance plasmids isolated from $S$. aureus strains collected in Australia between 1947 and 1965 (Gillespie et al., 1985), while revealing the existence of $\mathrm{Pc}^{\mathrm{r}}$ elements with homologous bla and inv segments, showed that inv in these elements was often capable of inversion or was maintained in the (+) orientation (M. Gillespie \& R. Skurray, unpublished). In this respect, the $\mathrm{Pc}^{\mathrm{r}}$ elements detected on Australian heavy-metal-resistance plasmids mirrored those found elsewhere during this period (Murphy \& Novick, 1979; Shalita et al., 1980).

\section{Detection of Tn4002 on S. aureus chromosomes}

The majority of $\mathrm{Pc}^{\mathrm{r}} S$. aureus collected in Australia since the early 1970s were found to possess chromosomally-encoded $\beta$-lactamase (Gillespie et al., 1985) which, in some instances, was shown to be $\mathrm{Tn} 4002$ on the basis of translocation to a resident plasmid (see above). Such strains were therefore examined for the presence of chromosomal sequences homologous to $\operatorname{Tn} 4002$, using hybridization probes for bla and inv consisting of the $0.8 \mathrm{~kb} H$ indIII-XbaI and $1.65 \mathrm{~kb}$ $B g / I I-P v u I I$ fragments of pSK74, respectively (Fig. 3).

Hybridization of HaelII-digested whole-cell DNA from six of seven $S$. aureus strains exhibiting chromosomal $\beta$-lactamase production with the $b l a$-specific probe revealed a $2.55 \mathrm{~kb}$ HaeIII fragment of identical size to that detected in digests of heavy-metal-resistance plasmids, pSK1 family plasmids and self-transmissible plasmids encoding $\mathrm{Pc}^{\mathrm{r}}$, thereby suggesting that homologous determinants are responsible for both plasmid and chromosomal $\mathrm{Pc}^{\mathrm{r}}$; in the remaining isolate, SK 1903, an $8.7 \mathrm{~kb}$ HaeIII fragment hybridized with the probe (data not presented). However, bla-specific hybridization with HindIII digests of whole-cell DNA from these strains revealed that a $4.5 \mathrm{~kb}$ HindIII fragment hybridized with the probe in strains which possessed bla sequences on the $2.55 \mathrm{~kb}$ HaeIII fragment (Fig. $4 a$, lanes D, E, F, H, I and J), whereas SK 1903 (Fig. 4a, lane G) carried bla sequences on a $1.3 \mathrm{~kb}$ HindIII fragment. Therefore, neither of the chromosomal HindIII fragments with bla homology was equivalent to the bla-containing HindIII fragments of pSK 74 (Fig. $4 a$, lane A), pSK 4 or pUW3626, indicating that such plasmids had probably not integrated, in their entirety, into the genome. Further support for this notion resulted from the finding that a mercury-resistance region, highly related to that found on $\beta$-lactamase/heavy-metal-resistance plasmids, physically maps on the chromosome in strains such as SK460, SK 1589, SK1660, SK1717, and SK 1734 (Table 1) not in association with other $\beta$-lactamase/heavy-metal plasmid sequences but with the determinants for methicillin and tetracycline resistance (Gillespie et al., 1987a; Matthews et al., 1987; M. Gillespie \& R. Skurray, unpublished data).

To determine if the chromosomal $\beta$-lactamase regions also possessed an invertible region and therefore represented a complete $\mathrm{Pc}^{\mathrm{r}}$ element such as $\mathrm{Tn} 552$ or $\mathrm{Tn} 4002$, appropriately digested whole-cell DNA was hybridized with the inv-specific probe. The six chromosomal strains which exhibited similar HaeIII and HindIII fragments when hybridized with the bla-specific probe were found to possess an equivalent $8.1 \mathrm{~kb}$ HindIII fragment with homology to inv; this fragment did not correspond in size with the inv-specific HindIII fragments of pSK 74, pSK 4 or pUW3626 (data not presented). As with the bla sequences, the chromosomal inv sequences are 
(a) A B C D E F G H I J

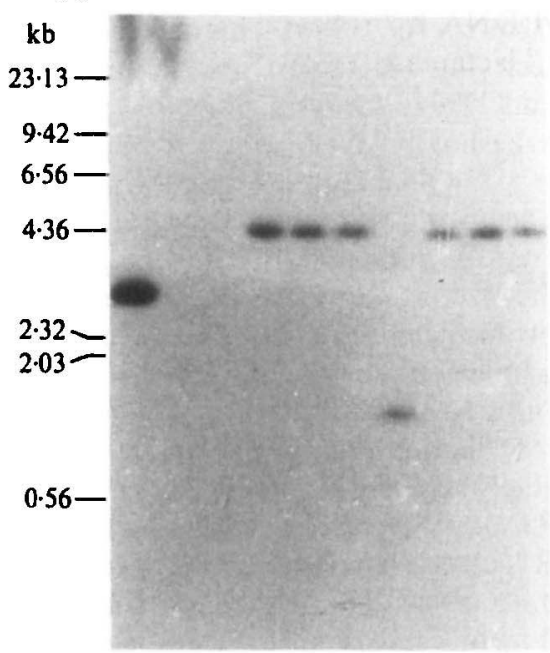

(b) A B

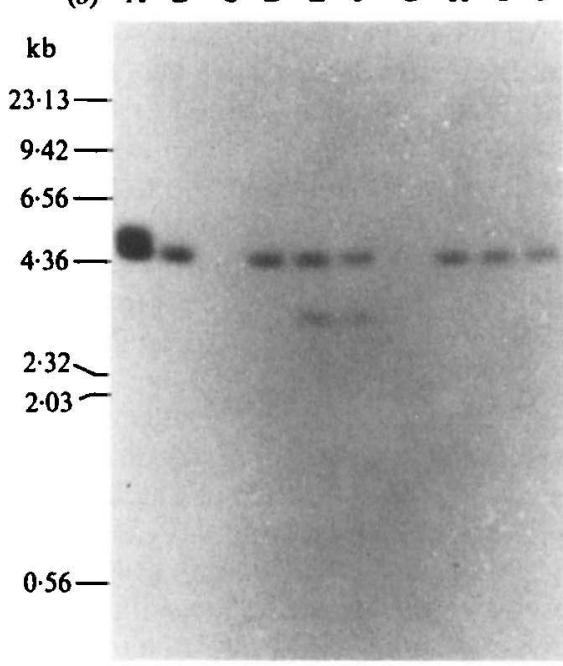

Fig. 4. (a) Autoradiograph following hybridization of HindIII-cleaved $S$. aureus plasmid and whole-cell DNA with a specific probe for bla sequences comprising the $0.8 \mathrm{~kb}$ HindIII-XbaI fragment of pSK 74 . Lanes: A, pSK74; B, 一; C, SK1655; D, SK1660; E, SK1717; F, SK1734; G, SK 1903; H, SK460; I, SK1589; J, SK1591. Molecular size markers (HindIII-cleaved $\lambda$ phage DNA) are shown at left. (b) Autoradiograph following hybridization of $B g l \mathrm{II}$ - and $H$ indIII-cleaved $S$. aureus plasmid and wholecell DNA with a specific probe for inv sequences comprising the $1.65 \mathrm{~kb} B g / \mathrm{II}-P v u \mathrm{II}$ fragment of pSK 74. Lanes: A, pSK 74; B, pSK4; C, SK1655; D, SK1660; E, SK1717; F, SK1734; G, SK1903; H, SK 460; I, SK1589; J, SK 1591. Molecular size markers (HindIII-cleaved $\lambda$ phage DNA) are shown at left.

seemingly contiguous with genomic and not integrated plasmid DNA. Two strains, SK 1717 and SK1734, each demonstrated an additional HindIII fragment with inv sequence homology, thereby suggesting that the chromosomes of these strains possess two copies of inv; the $\beta$ lactamase producing and non-producing isolates, SK 1903 and SK1655, respectively (Fig. $4 a$, lanes $\mathrm{G}$ and $\mathrm{C}$ ), failed to hybridize with the inv-specific probe, indicating that neither strain carries inv sequences. Hence, although SK 1903 possesses bla sequences, it does not carry an element equivalent to $\mathrm{Tn} 4002$.

Having established the presence of both bla and inv sequences on the chromosomes of several $\mathrm{Pc}^{\mathrm{r}} S$. aureus, whole-cell DNA was digested with $B g l \mathrm{II}$ and HindIII and hybridized with the invspecific probe to confirm the contiguity of the two regions (as shown in Fig. 3) and to determine the orientation(s) of the invertible region in each case. A Bg/II-HindIII fragment of $4.5 \mathrm{~kb}$ hybridized with this probe in those six isolates which carried chromosomal $\beta$-lactamase and exhibited inv sequence homology (Fig. $4 b$, lanes D, E, F, H, I and J). This fragment was equivalent in size to that produced by Tn 4002 in pSK4 (Fig. $4 b$, lane B) and to that resulting from the (-) orientation of inv in pSK 74 (Fig. $4 b$, lane A); the $4.8 \mathrm{~kb} \mathrm{BglII}-H i n d I I I$ fragment of pSK 74 with inv homology resulted from the $(+)$ orientation of inv (Fig. $4 b$, lane A). Strains SK 1717 and SK 1734 (Fig. $4 b$, lanes E and F) each demonstrated an additional $3.2 \mathrm{~kb}$ fragment with inv sequence homology which presumably resulted from the extra copy of inv on the chromosomes of these strains.

The finding that the chromosomal inv in the (-) orientation is located adjacent to the bla locus, together with the evidence presented above indicating that this $\beta$-lactamase region is not associated with an integrated plasmid, suggests that the chromosomes of a number of the $\mathrm{Pc}^{\mathrm{r}} S$. aureus strains isolated in Australia since 1976 (Table 1) possess copies of a $\mathrm{Pc}^{\mathrm{r}}$ element equivalent to Tn4002. Such evidence reinforces the idea that the presence of Tn4002 on the pSK 1 family of plasmids in clinical isolates may have resulted from the transposition of this element from the chromosome, an event equivalent to the transposition we have detected with laboratory-derived insertions of Tn4002 into pSK1. 
The chromosomal $\beta$-lactamase determinant described by Asheshov (1969) has also been shown to be transposable and is designated Tn552 (Shalita et al., 1980). This designation results from the observation that a $6.1 \mathrm{~kb}$ DNA segment specifying $\beta$-lactamase production transposed from its chromosomal location in staphylococcal strain 9789 to the resident Pcs plasmid pI9789, thereby constructing the Pcr plasmid pRN4115 (Asheshov, 1969; Murphy \& Novick, 1979). Tn 552 was subsequently found to be identical to the pI524 $\beta$-lactamase region, which included the bla determinant and in $v$ as a reversibly invertible segment (Murphy \& Novick, 1979 ; Shalita et al., 1980). However, from the reported size of $\operatorname{Tn} 552(6 \cdot 1 \mathrm{~kb})$ and that for the $\beta$-lactamase region of pI524 $(6.8 \mathrm{~kb})$ a discrepancy of $0.7 \mathrm{~kb}$ (the size of one of the IRs of inv) is evident (Murphy \& Novick, 1979). Comparison of the reported restriction endonuclease fragment sizes of pI9789 (Shalita et al., 1980) indicates that this plasmid contains a $0.7 \mathrm{~kb}$ DNA segment near the position at which inv would be located following transposition of Tn552. This led to the suggestion that pI9789 carries one of the IRs of inv (Shalita et al., 1980) and it is therefore possible that transposition of Tn 552 to a site immediately adjacent to this IR sequence in pI9789 could result in a $\beta$-lactamase region equivalent to that of pI524. Alternatively, such a structure might have arisen by recombination between the IR located on Tn552 and that proposed to be present on p19789. Such IR-mediated recombination/translocation might also explain the sitespecificity of the Tn552 insertion to this plasmid (Murphy \& Novick, 1979). If this argument is correct, Tn552 would contain only one IR sequence of $i n v$, thereby making the three transposons $\mathrm{Tn} 552$, Tn 4002 and $T n 4201$ very close relatives. It would also then be likely that the inv of Tn552 on the chromosome of strain 9789 is in the (-) orientation, as with inv on $\operatorname{Tn} 4002, \operatorname{Tn} 4201$ and pUW3626, since the second IR $\left(I_{R}\right)$ is essential for reversible inversion to take place. $I R_{R}$ has recently been demonstrated to encode a DNA invertase, Bin, related to the Hin family of sitespecific recombinases; bin may also be implicated in the transposition of these $\mathrm{Pc}^{\mathrm{r}}$ elements (Rowland \& Dyke, 1988).

\section{Evolution of $\beta$-lactamase transposons in $S$. aureus}

The preceding evidence suggests an interesting scenario for the evolution of $\mathrm{Pc}^{\mathrm{r}}$ in Australian $S$. aureus strains over the last 40 years. Resistance to penicillin in the majority of isolates during the first 20 years of antibiotic therapy was mediated by heavy-metal-resistance plasmids carrying elements such as Tn552 (Gillespie et al., 1985; M. Gillespie \& R. Skurray, unpublished). The 1970s saw the emergence of strains exhibiting chromosomal $\mathrm{Pc}^{\mathrm{r}}$, presumably as a result of the transposition of Tn552-like elements to the chromosome rather than the integration of entire $\beta$-lactamase/heavy-metal-resistance plasmids. In the strains we have examined, the latter is improbable given the failure to detect contiguous plasmid sequences at the chromosomal $\beta$-lactamase locus and the inability of chromosomal inv sequences to undergo reversible inversion. Within the same decade two new families of plasmids became associated with $\mathrm{Pc}^{\mathrm{r}}$ elements, as the self-transmissible plasmids in isolates from the USA gained elements such as Tn4201, perhaps through cohabitation with compatible heavy-metal-resistance plasmids (Gray et al., 1983), and the pSK1 family of plasmids in multiresistant Australian isolates almost certainly acquired Tn4002 from a chromosomal site. The underlying reasons for this evolutionary course are obscure, but are undoubtedly a response to changing selection pressures in the hospital environment and may well be linked to antibiotic therapy practices of the periods in question.

The $\mathrm{Pc}^{\mathrm{r}}$ elements $\mathrm{Tn} 552$, Tn4002 and Tn4201 have presumably diverged from a common ancestor and further analysis should shed light on the molecular rearrangements involved in this process. Of particular interest for future study is the specificity of insertion exhibited by these elements. Tn552 (Murphy \& Novick, 1979) and Tn4201 (Weber \& Goering, 1988) both show specificity of insertion for particular regions of plasmid vectors, or in the case of the latter, the chromosome. With Tn552 the specificity is for the invertible region IR, and, as pointed out above, such an insertion may result from IR-specific recombination/translocation rather than conventional transposition. In contrast to these elements, Tn4002 was shown to be inserted at demonstrably different sites within a $600 \mathrm{bp}$ region of the pSK 1 family of plasmids but, like Tn4201, occupied an identical chromosomal site in six distinct strains. Such evidence suggests 
that Tn 4002 had translocated from a single chromosomal site to the co-resident pSK1 plasmid on a number of occasions. The two copies of Tn4002 in pSK 11 may reflect secondary insertion when the preferred region is occupied, or may alternatively represent intramolecular transposition. The fact that a transposable element with such apparently complex specificity is compatible with at least three radically different plasmid vectors, together with the chromosome, suggests an intimate evolutionary development of all of these components.

We wish to thank Linda Messerotti for technical assistance. This work was supported in part by a Project Grant from the National Health and Medical Research Council (Australia). M.T.G. and B.R.L. were recipients of Commonwealth Postgraduate Research Awards.

\section{REFERENCES}

AsHeSHOv, E. H. (1969). The genetics of penicillinase production in Staphylococcus aureus strain PS80. Journal of General Microbiology 59, 289-301.

Gillespie, M. T. \& SkURRAY, R. A. (1986). Plasmids in multiresistant Staphylococcus aureus. Microbiological Sciences 3, 53-58.

Gillespie, M. T., May, J. W. \& Skurray, R. A. (1985). Antibiotic resistance in Staphylococcus aureus isolated at an Australian hospital between 1946 and 1981. Journal of Medical Microbiology 19, 137-147.

Gillespie, M. T., May, J. W. \& Skurray, R. A. $(1986 a)$. Detection of an integrated tetracycline resistance plasmid in the chromosome of methicillinresistant Staphylococcus aureus. Journal of General Microbiology 132, 1723-1728.

Gillespie, M. T., May, J. W. \& Skurray, R. A. $(1986 b)$. Plasmid-encoded resistance to acriflavine and quaternary ammonium compounds in methicillin-resistant Staphylococcus aureus. FEMS Microbiology Letters 34, 47-51.

Gillespie, M. T., Lyon, B. R., LOO, L. S. L., Matthews, P. R., Stewart, P. R. \& Skurray, R. A. (1987a). Homologous direct repeat sequences associated with mercury, methicillin, tetracycline and trimethoprim resistance determinants in Staphylococcus aureus. FEMS Microbiology Letters 43, 165-171.

Gillespie, M. T., Lyon, B. R., Messerotti, L. J. \& Sxurray, R. A. (1987b). Chromosome- and plasmid-mediated gentamicin resistance in Staphylococcus aureus encoded by Tn4001. Journal of Medical Microbiology 24, 139-144.

Goering, R. V. \& RufF, E. A. (1983). Comparative analysis of conjugative plasmids mediating gentamicin resistance in Staphylococcus aureus. Antimicrobial Agents and Chemotherapy 24, 450-452.

Goering, R. V., Teeman, B. A. \& Ruff, E. A. (1985). Comparative physical and genetic maps of conjugal plasmids mediating aminoglycoside resistance in Staphylococcus aureus strains in the United States. Zentralblatt für Bakteriologie (Suppl.) 14, 625-628.

Gray, G. S., Huang, R. T.-S. \& Davies, J. (1983). Aminocyclitol resistance in Staphylococcus aureus: presence of plasmids and aminocyclitol-modifying enzymes. Plasmid 9, 147-158.

LYON, B. R. \& SKURRAY, R. A. (1987). Antimicrobial resistance of Staphylococcus aureus: genetic basis. Microbiological Reviews 51, 88-134.
Lyon, B. R., May, J. W. \& Skurray, R. A. (1983). Analysis of plasmids in nosocomial strains of multiple-antibiotic-resistant Staphylococcus aureus. Antimicrobial Agents and Chemotherapy 23, 817-826.

Lyon, B. R., IUORIO, J. L., MaY, J. W. \& Skurray, R. A. (1984a). Molecular epidemiology of multiresistant Staphylococcus aureus in Australian hospitals. Journal of Medical Microbiology 17, 79-89.

Lyon, B. R., May, J. W. \& SkURRay, R. A. (1984b). Tn4001: a gentamicin and kanamycin resistance transposon in Staphylococcus aureus. Molecular and General Genetics 193, 554-556.

Lyon, B. R., GILleSPIE, M. T., BYRNE, M. E., MAY, J. W. \& Skurray, R. A. (1987). Plasmid-mediated resistance to gentamicin in Staphylococcus aureus: the involvement of a transposon. Journal of Medical Microbiology 23, 101-110.

Matthews, P. R., Reed, K. C. \& Stewart, P. R. (1987). The cloning of chromosomal DNA associated with methicillin and other resistances in Staphylococcus aureus. Journal of General Microbiology 133, 1919-1929.

Mclaughlin, J. R., Murray, C. L. \& Rabinowitz, J. C. (1981). Unique features in the ribosome binding site sequence of the Gram-positive Staphylococcus aureus $\beta$-lactamase gene. Journal of Biological Chemistry 256, 11283-11291.

Murphy, E. \& Novick, R. P. (1979). Physical mapping of Staphylococcus aureus penicillinase plasmid pI524: characterization of an invertible region. Molecular and General Genetics 175, 19-30.

Peyru, G., Wexler, L. F. \& Novick, R. P. (1969). Naturally occurring penicillinase plasmids in Staphylococcus aureus. Journal of Bacteriology 98, 215-221.

Rowland, S.-J. \& Dyke, K. G. H. (1988). A DNA invertase from Staphylococcus aureus is a member of the Hin family of site-specific recombinases. FEMS Microbiology Letters 50, 253-258.

Shalita, Z., Murphy, E. \& Novick, R. P. (1980). Penicillinase plasmids of Staphylococcus aureus: structural and evolutionary relationships. Plasmid 3, 291-311.

SKurRay, R. A., Rouch, D. A., Lyon, B. R., Gillespie, M. T., Tennent, J. M., Byrne, M. E., Messerotti, L. J. \& MAY, J. W. (1988). Multiresistant Staphylococcus aureus: genetics and evolution of epidemic Australian strains. Journal of Antimicrobial Chemotherapy 21, Suppl. C, 19-38. 
Wang, P.-Z. \& Novick, R. P. (1987). Nucleotide sequence and expression of the $\beta$-lactamase gene from Staphylococcus aureus plasmid pI 258 in Escherichia coli, Bacillus subtilis, and Staphylococcus aureus. Journal of Bacteriology 169, 1763-1766.

Weber, D. A. \& Goering, R. V. (1988). Tn4201, a beta-lactamase transposon in Staphylococcus aureus. Antimicrobial Agents and Chemotherapy (in the Press).
WitTE, W. \& DüNNhauPT, K. (1984). Occurrence of a nonplasmid-located determinant of gentamicin resistance in strains of Staphylococcus aureus. Journal of Hygiene 93, 1-8.

YounG, H.-K., Skurray, R. A. \& Amyes, S. G. B. (1987). Plasmid-mediated trimethoprim-resistance in Staphylococcus aureus. Characterization of the first Gram-positive plasmid dihydrofolate reductase (type S1). Biochemical Journal 243, 309-312. 